\title{
Estimation of Traction Drive Test Bench with Energy Storage System Operation in Regenerative Braking Mode
}

\author{
Genadijs Zaleskis (M.sc.ing., Riga Technical University - RTU), Viesturs Brazis (Dr.sc.ing., RTU), \\ Leonards Latkovskis (Dr.sc.ing., RTU, Institute of Physical Energetics)
}

\begin{abstract}
The paper presents configuration of the traction drive test bench with energy storage system, calculation of the scale factors, estimation of the energy storage system size and Matlab simulation results of the bench operation in a braking mode at different levels of the supercapacitor initial voltage.
\end{abstract}

Keywords - Motor drives, computer simulation, energy storage, supercapacitors.

\section{INTRODUCTION}

The increase in efficiency of passenger electrical transport can be reached by a way of use of on-board energy storage systems (ESS). The modern and reconstructed vehicles can regenerate the accumulated kinetic energy back to a network, but in most cases the substations are equipped with uncontrollable rectifiers therefore this method is applicable only in that case when another vehicle starts movement at the same contact network section. Otherwise the accumulated energy dissipates in braking resistors. Hybrid energy storage systems allow braking energy saving for further use by a vehicle for acceleration, autonomous traction without connection to a network, lighting or heating. Feature of hybrid ESS (Fig. 1.) is the combination of different type storage devices (supercapacitor, accumulator battery or flywheel).

The stored energy can be used in the case of voltage interruptions. They appear when the tramcar overcomes network section insulators or when the current collector jumps on a contact network wire. Results of vehicle movement modeling with ESS in the case of voltage interruptions are described in [1] and [2].

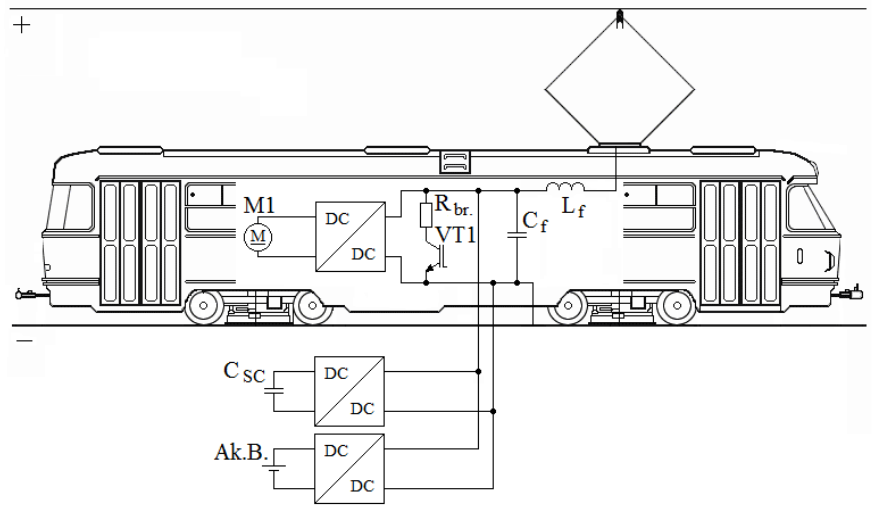

Fig. 1. Tramcar traction drive with hybrid energy storage system.
For hybrid ESS research the stationary test bench is necessary, because the full-scale experiments disturb the scheduled traffic, and therefore could be run only in the offpeak time or using special test tracks. Use of the laboratory test bench with power scale $3-5 \mathrm{~kW}$ allows to reduce the number of real vehicle test runs. Besides, the high power and high voltage transport systems are unsafe and inconvenient for educational purposes and scientific research.

Similar test benches are described in [3] and [4], but they are not intended for vehicle modeling with the DC traction motor, namely such motors are used in the reconstructed vehicles of the Riga tram park which can be in service up to 2032 [5]. Besides, the bench described in [3] does not allow possibility to test the traction motor and ESS at different mechanical loads corresponding to different mass of a vehicle.

In [6] the test bench with DC traction motor configuration is described, but the main disadvantage of this system is DC motor using as a load machine in mechanical load simulator. The reasons are the difficulties in control and maintenance in comparison with the asynchronous machine. Besides, the solutions described in [3], [4] and [6] do not provide the use of hybrid energy storage systems.

The test bench described in [7] and [1] is developed for providing all research requirements.

The main idea of the article is the estimation of the traction drive test bench with ESS overall performance in the regenerative braking mode by means of Matlab/Simulink model [1]. This simulation is necessary for an optimum choice of the test bench parameters and control methods. The battery is inapplicable for short-term energy storage for the purpose of power maximum alignment and regenerated energy storage. Accumulator battery may be used only as a power supply. The capacity of the supercapacitor used in the test bench is too high in relation to the traction power therefore in the article the results of the ESS scaling are presented.

\section{TEST BENCH SCHEME AND PARAMETERS}

\section{A. Test Bench Scheme and Motor Parameters}

The tramcar drive with four motors is replaced by a traction drive model containing an equivalent independent excitation DC motor. The model's motor is connected to the DC bus through the DC/DC converter which provides simulation of traction and braking modes without reversing the rotational direction. In the existing trams the mechanical backward 
direction switch is applied but seldom due to their singledirection design [7].

The DC motor applied in the test bench has the following parameters:

$P_{\text {nom }}=3.7 \mathrm{~kW}$ - rated power of the motor;

$r_{a}-0.46 \Omega-$ resistance of an armature circuit;

$n_{\text {nom }}-1370 \mathrm{rpm}$ - rated speed of the motor;

$C_{E}=0.6366-$ an electromagnetic constant of the motor.

The DC bus is connected to the $110 \mathrm{~V}$ DC power supply through a diode VD simulating a unidirectional traction substation [1]. A large capacitor $C_{f}$ is equivalent to the vehicle traction drive filter capacitor. The voltage limiter with braking resistor $R_{v l}$ is necessary for overvoltage prevention on the DC bus.

The traction DC motor is mechanically coupled to the asynchronous machine which together with the frequency converter forms a load simulator [7]. The AC motor is connected to the frequency converter output and has the following parameters:

$n_{A C}=1450 \mathrm{rpm}-$ rated speed of the motor;

$V_{A C}=380 \mathrm{~V}, 50 \mathrm{~Hz}$ - rated voltage and frequency;

$P_{A C}=4 \mathrm{~kW}$ - rated power of the motor.

\section{B. Hybrid Energy Storage System}

Feature of hybrid ESS is the combination of different type storage devices (supercapacitor, accumulator battery or flywheel). Each type has its own characteristics and therefore own advantages and disadvantages [8].

Batteries have a limited specific power $(\mathrm{W} / \mathrm{kg}$ ) regarding absorbing and delivering energy compared to flywheels and supercapacitors. On the other hand, flywheels and supercapacitors have a more limited specific energy $(\mathrm{Wh} / \mathrm{kg})$ compared to batteries. Supercapacitors can contain more specific power compared to flywheels.

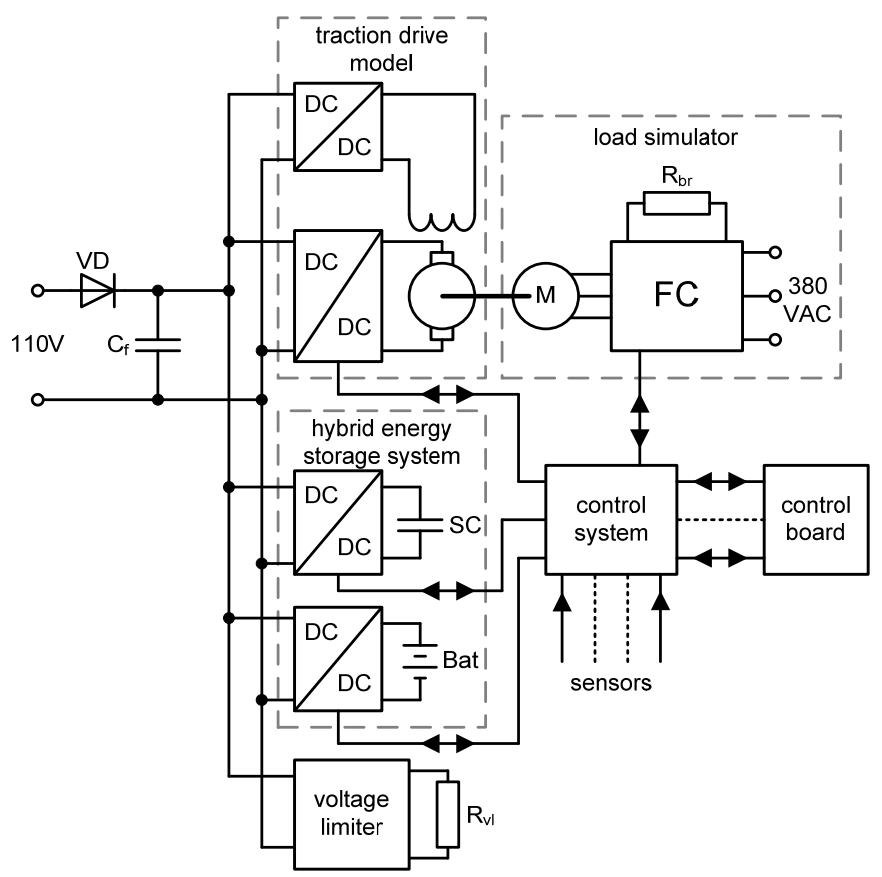

Fig. 2. Simplified diagram of the traction drive test bench with a hybrid energy storage system.
The hybrid ESS allows using advantages of supercapacitors and accumulator batteries depending on a vehicle operating mode. Accumulator batteries can be used to supply vehicles systems and support the relatively high distance autonomous traction mode, but supercapacitor is the most favorable for autonomous auxiliary traction, power maximum alignment and braking energy saving [9].

The hybrid energy storage system of the test bench includes the supercapacitor Maxwell BMOD0063-P125-B01 with the $125 \mathrm{VDC}$ rated voltage and capacity $63 \mathrm{~F}$ and the accumulator battery consisting of eight elements Panasonic LC-RA1212PG with the $12 \mathrm{~V}$ of DC rated voltage each.

As the accumulator battery is not suitable for power maximum alignment and braking energy saving, the modeling for the supercapacitor only is presented in this article. Possibility of a continuous charging of the accumulator battery independent on a vehicle operating mode was presented in [1]. In this case the flywheel is not used, as the stores of this type have much higher power, than the traction drive test bench parameters.

\section{TESt BENCH SCALING}

\section{A. Traction Drive Model Scaling}

For vehicle simulation on the test bench all its equipment, including energy storages, should be scaled. Factors for scaling of the load simulator are given in [7].

The traction drive model scaling is made on the basis of Tatra T3M tramcar parameters:

$$
\begin{aligned}
& P_{\text {tram, nom }}=180 \mathrm{~kW}-\text { rated power of all tramcar motors; } \\
& P_{\text {tram, } \max }=316 \mathrm{~kW}-\text { maximal tramcar power; } \\
& n_{\text {tram, nom }}=1720 \mathrm{rpm} \text { - rated speed of the motor; } \\
& k_{\text {gear }}=7.36 \text { - vehicle gear box ratio; } \\
& m_{0}=18.5 \mathrm{t}-\text { mass of an empty tramcar; } \\
& m_{\text {max }}=30.2 \mathrm{t} \text { - mass of a full tramcar; } \\
& D=0.7 \mathrm{~m}-\text { wheel diameter. }
\end{aligned}
$$

Depending on the motor rotation speed, linear speed of the tram is

$$
v=\frac{3.6 \cdot \pi \cdot D}{60 \cdot k_{\text {gear }}} \cdot n=0.0179 \cdot n[\mathrm{~km} / \mathrm{h}]
$$

At the rated motor rotation frequency vehicle speed is $v_{\text {nom }}=$ $30.8 \mathrm{~km} / \mathrm{h}$ or $8.56 \mathrm{~m} / \mathrm{s}$.

Rated force is

$$
F_{\text {tram }, \text { nom }}=\frac{P_{\text {tram }, \text { nom }}}{v_{\text {nom }}} .
$$

Rated acceleration for an empty vehicle is

$$
a_{\text {nom }}=\frac{F_{\text {tram }, \text { nom }}}{m_{0}} .
$$


Accepting that the rated tram motor rotation frequency corresponds to the rated test bench DC motor rotation frequency, the equivalent force is

$$
F_{e k v}=\frac{P_{\text {nom }}}{v_{\text {nom }}} .
$$

To equivalent force there corresponds the equivalent mass

$$
m_{0 e k v}=\frac{F_{e k v}}{a_{n o m}} .
$$

Thus, the mass scale factor is

$$
k_{m}=\frac{m_{0}}{m_{0 e k v}},
$$

the power scale factor is

$$
k_{P}=\frac{P_{\text {tram,max }}}{P_{\text {nom }}},
$$

the force scale factor is

$$
k_{F}=\frac{F_{\text {tram }, \text { nom }}}{F_{\text {ekv }}} \text {, }
$$

the speed scale factor is

$$
k_{n}=\frac{n_{\text {tram }, \text { nom }}}{n_{\text {nom }}} .
$$

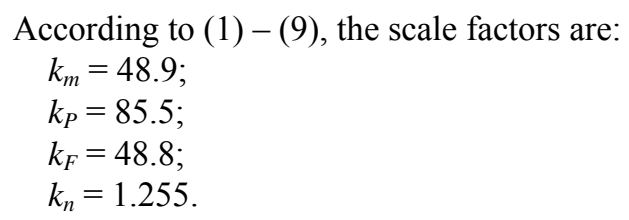

\section{B. ESS Scaling}

The size of vehicle ESS may be determined with two parameters: energy capacity $E_{E S S, v e h i c l e}$ and power capability (at

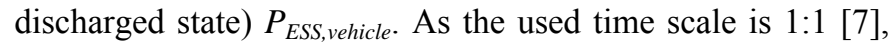
the relevant bench ESS parameters are calculated as

$$
\begin{aligned}
& P_{E S S, \text { bench }}=\frac{P_{E S S, \text { vehicle }}}{k_{P}}, \\
& E_{E S S, \text { bench }}=\frac{E_{E S S, \text { vehicle }}}{k_{P}} .
\end{aligned}
$$

On the other hand, these parameters for supercapacitor ESS of capacity $C$ and operational voltage range $V_{S C \text {,min }}-V_{S C, \text { max }}$ are determined by the equations:

$$
\begin{gathered}
P_{E S S, \text { bench }}=V_{S C, \min } \cdot I_{S C, \max }, \\
E_{E S S, \text { bench }}=\frac{\left(V_{C, \max }^{2}-V_{C, \min }^{2}\right) \cdot C}{2},
\end{gathered}
$$

where $I_{S C \text {,max }}$ is the set reference value of the converter current control loop, restricted rather for converter than supercapacitor protection.

Equations (11) - (14) may be used for both development of a new energy storage or adaptation of existing one for the test bench purposes. In the last case, first, the minimum voltage is calculated with chosen $I_{S C \text {, max }}$

$$
V_{S C, \min }=\frac{P_{E S S, \text { bench }}}{I_{S C, \max }},
$$

then the maximum voltage is

$$
V_{S C, \max }=\sqrt{\frac{2 \cdot E_{E S S, \text { bench }}}{C}+V_{S C, \min }^{2}} .
$$

Calculated value $V_{S C \text {, max }}$ should be less than the allowed voltage for supercapacitor bank.

If T3M tramcar is equipped with mentioned in [10] storage with $C_{\text {vehicle }}=33.3 \mathrm{~F} ; V_{S C \text {,max,vehicle }}=450 \mathrm{~V} ; V_{S C \text {,min,vehicle }}=$ $300 \mathrm{~V} ; I_{S C \text {,max }, \text { vehicle }}=700 \mathrm{~A}$, then:

$E_{E S S, v e h i c l e}=1873 \mathrm{~kJ}$;

$P_{E S S \text {,vehicle }}=210 \mathrm{~kW}$.

From (11) and (12) it can be concluded, that $E_{E S S, \text { bench }}=21.9$ $\mathrm{kJ} ; P_{E S S \text {,bench }}=2.46 \mathrm{~kW}$.

Accepting $I_{C, \max }=40 \mathrm{~A}$, operational voltage range is:

$V_{S C \min }=61.5 \mathrm{~V}$;

$V_{S C \max }=66.9 \mathrm{~V}$.

\section{ESS OPERATION IN REGENERATIVE BRAKING MODE}

In the braking mode the traction drive of the vehicle operates as a generator. Energy $E_{b r}$ which is generated by the motor in this case [11] can be expressed as

$$
E_{b r} \approx K_{1} \cdot E_{\text {Kinetic }},
$$

where $K_{1}$ is factor depending on the internal losses of a vehicle, power auxiliaries etc.; $E_{\text {Kinetic }}$ is the vehicle kinetic energy. The value of $\mathrm{K}_{1}$ varies within the range 0.5-0.6.

In braking mode the braking power will be stored in the supercapacitor until the state of charge (SoC) value will not reach 1 [12]. SoC can be expressed as in (18)

$$
S o C=1-\frac{E_{b r}}{E_{S C \max }},
$$

where $E_{S C \max }$ is the maximal possible energy stored by the supercapacitor. 
In the cases when supercapacitor is fully charged, the surplus braking power is dissipated in the braking resistor to avoid DC bus overvoltage.

\section{V.SIMULATION RESULTS}

The Matlab/Simulink simulation is made in the overhead feeding mode at various initial voltages $V_{S C, 0}$ of the supercapacitor: $V_{S C \min }<V_{S C, 0}<V_{S C \max } ; V_{S C, 0}<V_{S C \min } ; V_{S C, 0}>$ $V_{S C \max }$. Acceleration, freewheeling and braking modes in time scale $1: 1$ were simulated. The most admissible armature current $I_{\text {arm }}=40$ A and power scale factor $k_{P}=85.5$ are used.

In the case when value of the supercapacitor initial voltage $V_{S C, 0}=64 \mathrm{~V}$ is between $V_{S C \min }$ and $V_{S C \max }$, the ESS discharge in the acceleration mode of a traction drive is possible. The ESS partially provides the traction motor with energy necessary for acceleration, as shown in Fig. 3. In the braking mode the supercapacitor charging is possible. Fig. 4 presents the power allocated and consumed by the ESS respectively in the acceleration and braking modes.


Fig. 3. Simulation diagram for $\mathrm{V}_{\mathrm{SC}, 0}=64 \mathrm{~V}$ (Itr - traction drive current; Isub substation current; Iess - ESS current; Iref - armature current reference; Iarm - armature current; VCf - filter capacitor voltage; Vsub - substation voltage; Vsc - supercapacitor voltage; Isc - supercapacitor current).

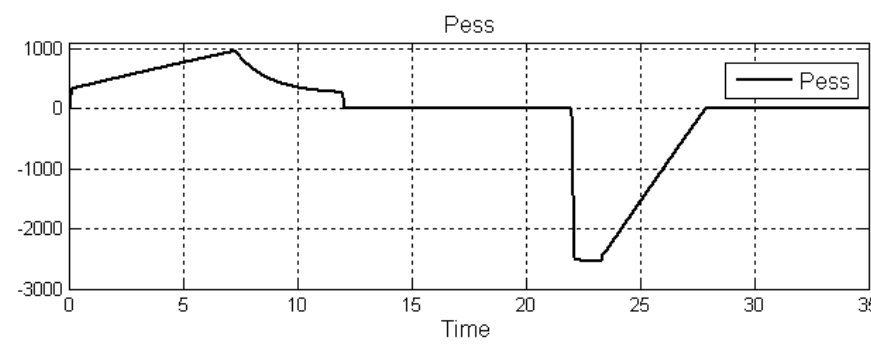

Fig. 4. Simulation diagram of the ESS power Pess in the case of $\mathrm{V}_{\mathrm{SC}, 0}=64 \mathrm{~V}$.

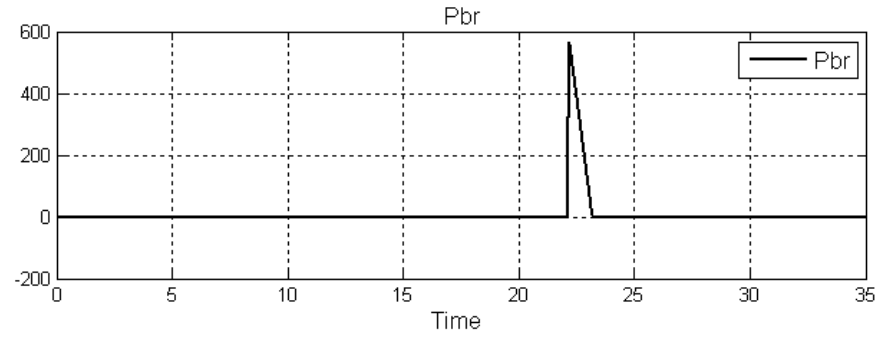

Fig. 5. Simulation diagram of the power Pbr dissipated in the braking resistor in the case of $\mathrm{V}_{\mathrm{SC}, 0}=64 \mathrm{~V}$.

To avoid the overvoltage across the DC bus, the part of braking energy dissipates in braking resistor $R_{v l}$ (Fig. 5.).

If the supercapacitor initial voltage $V_{S C, 0}=66.9 \mathrm{~V}$ is equal to high limit of an operational range (Fig. 6.), in a vehicle acceleration mode the supercapacitor is discharged insufficiently to accept all saved energy in the subsequent braking mode (Fig. 7.).
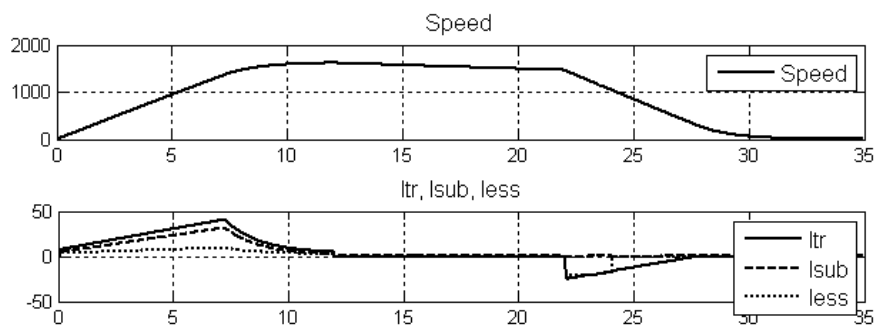

Iref, larm
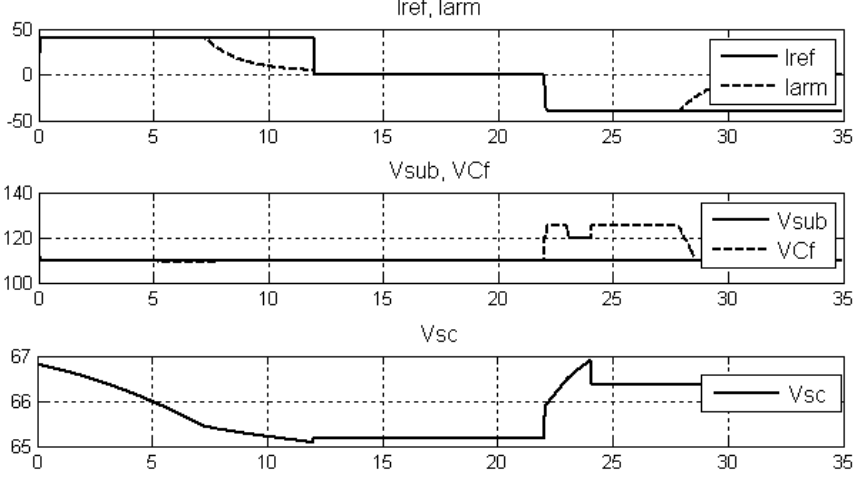

$\mathrm{Isc}$



Fig. 6. Simulation diagram for $\mathrm{V}_{\mathrm{SC}, 0}=66.9 \mathrm{~V}$. 


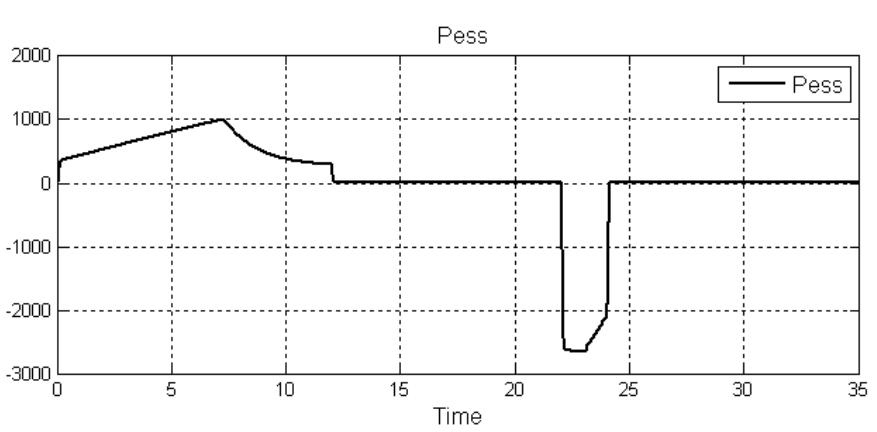

Fig. 7. Simulation diagram of the ESS power Pess in the case of $\mathrm{V}_{\mathrm{SC}, 0}=66.9$ V.

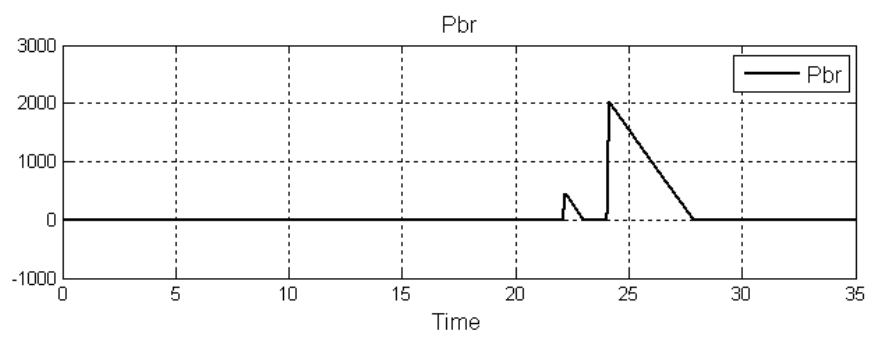

Fig. 8. Simulation diagram of the power Pbr dissipated in the braking resistor in the case of $\mathrm{V}_{\mathrm{SC}, 0}=66.9 \mathrm{~V}$.

In this case the brake resistor turns on two times. The first time it joins for power peak alignment, and the second time for dissipation of the remained braking energy (Fig. 8.).

In the case when the value of supercapacitor initial voltage $V_{S C, 0}=62.3 \mathrm{~V}$ is in the limits of the operational range and it is close to the low limit, SoC of the supercapacitor can not provide the enough energy for complete acceleration mode (Fig. 9.).
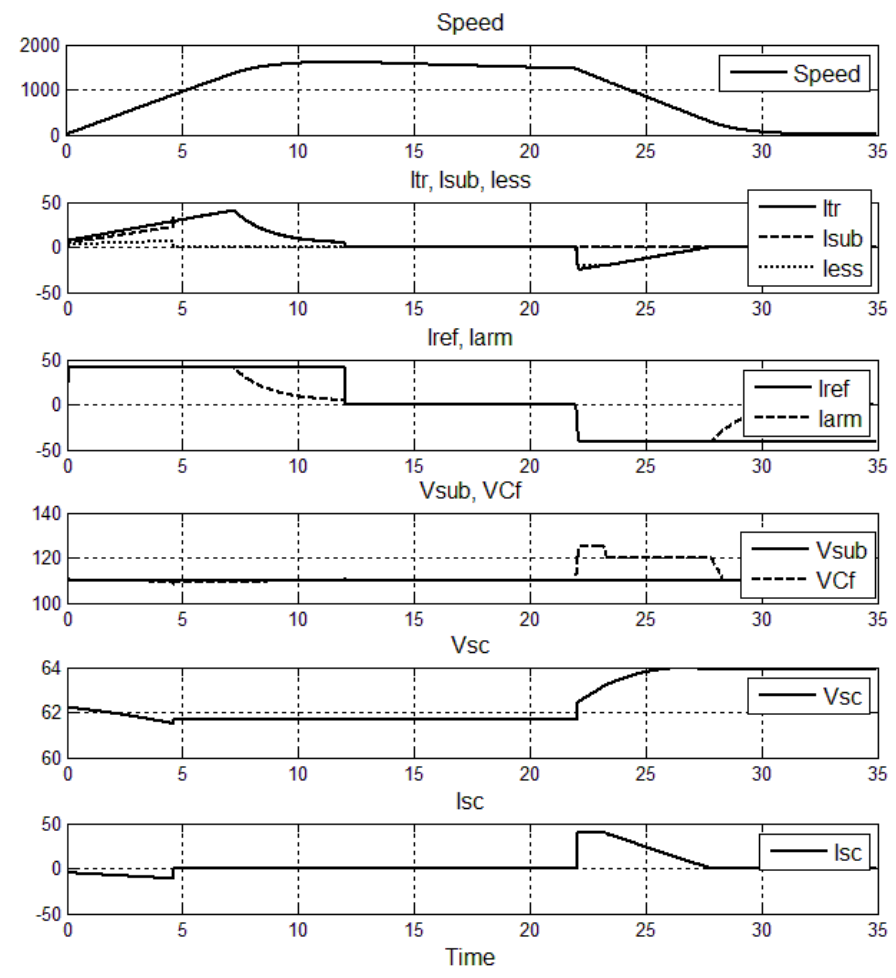

Fig. 9. Simulation diagram for $\mathrm{V}_{\mathrm{SC}, 0}=62.3 \mathrm{~V}$.



Fig. 10. Simulation diagram of the ESS power Pess in the case of $\mathrm{V}_{\mathrm{SC}, 0}=$ $62.3 \mathrm{~V}$.

When the supercapacitor voltage reaches the low limit, supercapacitor is disconnected. At the moment of supercapacitor disconnection an increasing of a substation current Isub is observed. In the mode of braking there is a supercapacitor charging (Fig. 10.).

If the supercapacitor initial voltage $V_{S C, 0}=70 \mathrm{~V}$ (higher, than $\left.V_{S C \max }\right)$ the ESS discharge in an acceleration mode is enabled. However, if after discharging the voltage level is still higher, than $V_{\text {SCmax }}$, a charging of the supercapacitor does not occur (Fig. 11.). Simulation also was made at the maximum armature current $I_{\text {arm }}=40 \mathrm{~A}$.

In a real vehicle this mode is inadmissible, as the supercapacitor initial voltage is higher than the high limit of the operational range, but it is possible while using test bench.

In this case all braking energy dissipates in a braking resistor as shown in Fig. 12.

From Fig. 12. it can be concluded, that for safe operation under the conditions when energy storage in the supercapacitor is impossible, the necessary minimum power of the braking resistor should be $3 \mathrm{~kW}$.

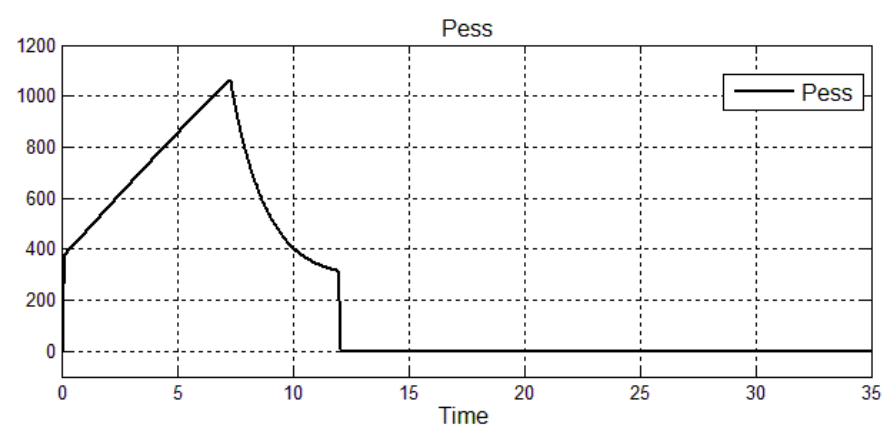

Fig. 11. Simulation diagram of the ESS power in the case of $\mathrm{V}_{\mathrm{SC}, 0}=70 \mathrm{~V}$.

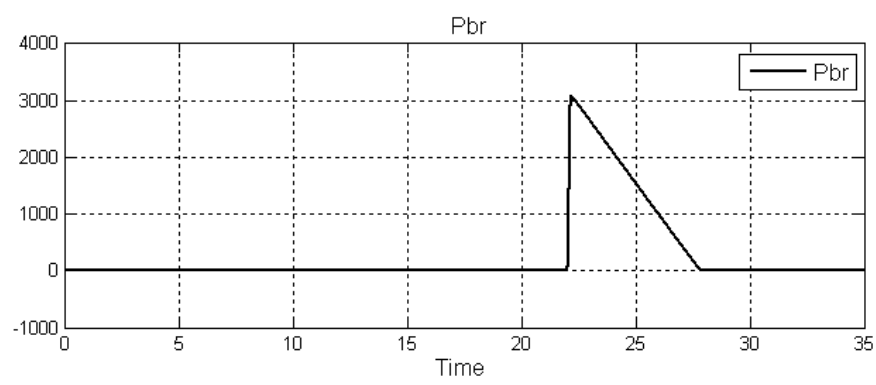

Fig. 12. Simulation diagram of the power dissipated in the braking resistor in the case of $\mathrm{V}_{\mathrm{SC}, 0}=70 \mathrm{~V}$. 


\section{Conclusions}

Correct operation of the test bench depends on the correct scaling therefore within this article scale factors are calculated, and operational range of supercapacitor voltage is set. Scaling of the energy storage system allows choosing optimum parameters for the supercapacitor to provide effective braking energy saving at minimum price and sizes. According to the scale, the operational voltage range of the supercapacitor used in the experiments is calculated. In the case when value of the supercapacitor initial voltage is in the operational range limits, the energy storage system allows the braking energy saving and partial providing the traction motor with energy in the acceleration mode. It is necessary to consider possible decrease in ESS effectiveness if initial voltage of the supercapacitor is too close to the operational range limits. The power of braking resistor should be higher than $3 \mathrm{~kW}$ for all braking energy dissipation in the case when regenerative braking energy saving by ESS is impossible.

\section{ACKNOWLEDGMENTS}

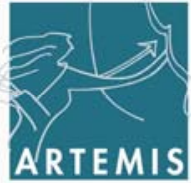

The research leading to these results has been funded from the ARTEMIS Joint Undertaking under grant agreement $n^{\circ}$ 269265 and from Latvian Academy of Science and Ministry of Education and Science.

\section{REFERENCES}

[1] V. Brazis, G. Zaleskis, L. Latkovskis, L. Grigans, U. Sirmelis: Simulation of Light Railway Traction Drive with Energy Storage System. Proceedings of the 52st Annual International Scientific Conference of Riga Technical University, Section "Power and Electrical Engineering", October 2011.

[2] N. Cobanov: Capacitive Energy Storage Device from Tram Auxiliary Power Supplies. AUTOMATIKA 48(2007) 3-4, - pp. 113-120.

[3] P. Drabek, L. Streit, M. Los: The Energy Storage System with Supercapacitor. 14th International Power Electronics and Motion Control Conference, EPE-PEMC, T9, 2010. - pp. 39-43.

[4] D. Iannuzzi: Improvement of the Energy Recovery of Traction Electrica Drives using Supercapacitors. 13th International Power Electronics and Motion Control Conference, EPE-PEMC 2008. - pp. 1492-1497.

[5] L. Latkovskis, V. Bražis: Application of supercapacitors for storage or regenerative energy in T3A tramcars. Latvian Journal of Physics and Technical Sciences, Rīga, N5-2007. - pp. 23-33.

[6] Y. Cheng, J. Van Mierlo, P. Lataire: Research and test platform for hybrid electric vehicle with the supercapacitor based energy storage. International Review of Electrical Engineering (I.R.E.E.), Vol. 3, N32008. - pp. 466-478.

[7] V.Brazis, G. Zaleskis, L. Latkovskis, L. Grigans: Traction Drive Load Simulator. Proceedings of the 52st Annual International Scientific Conference of Riga Technical University, Section "Power and Electrical Engineering", October 2011

[8] Richard T.M. Smokers, Arjan J.J. Dijkhuizen and Rob G. Winkel: Annex VII: Hybrid Vehicles Overview Report 2000, Chapter 4: Components for hybrid vehicles. 2000, pp. 5-12.

[9] Genadijs Zaleskis, Juris Kiploks, Viesturs Brazis: Hybrid Vehicle for Military Operations. Proceeding of the $11^{\text {th }}$ International Symposium "Topical Problems in the Field of Electrical and Power Engineering *

Doctoral School of Energy and Geotechnology II", Faculty of Power Engineering, Tallin University of Technology, Parnu, 2012. - pp. 84-87.

[10] L. Latkovskis, V. Brazis and L. Grigans: Simulation of On-Board Supercapacitor Energy Storage System for tatra T3A Type Tramcars. Chapter 14 in the In-tech book "Modeling, Simulation and optimization", Vukovar, Chroatia, 2010, pp. 307-329.

[11] R. Barrero, J. Van Mierlo and X. Tackoen: Enhanced Energy Storage Systems for Improved On-Board Light Rail Vehicle Efficiency. IEEE Vehicular Technology Magazine, 2008. - pp. 26-36.

[12] R. Barrero, X. Tackoen, J. Van Mierlo: Analysis and configuration of supercapacitor based energy storage system on-board light rail vehicles. EPE-PEMC 2008 Conference Proceedings, Poznan, 2008. - pp. 15351540 .

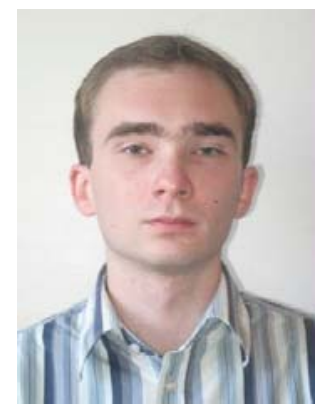

genadijs.zaleskis@rtu.lv

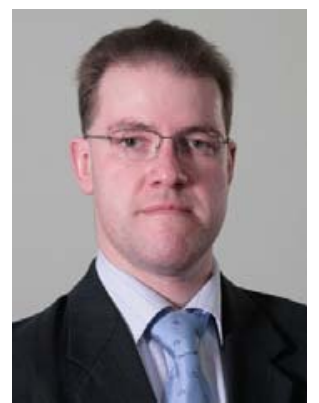

Genadijs Zaleskis, M. sc. ing., doct. student. He graduated from Riga Technical University in 2011 as Master of electrical engineering.

From 2010-2011 he worked at the Institute of Industrial Electronics and Electrical Engineering of Riga Technical University as laboratory technician. In 2011 he started his doctoral studies in RTU. Since 2011 he is working at the Department of Industrial Electronics and Electrical Technologies of Riga Technical University as a researcher.

Address: Kronvalda 1, Riga, LV1048.

Phone +371 28380 558,

Viesturs Brazis, associated professor, Dr. sc. ing. He graduated from Riga Technical University in 2000 as Master of electrical engineering. Defended his degree of Dr. sc. ing. in 2005 at Riga Technical university.

From 2001-2006 he worked as assistant, from 2006-2009 as docent at Riga Technical University. Research interests are connected with Electric drives, Power electronics and Industrial automation. Now is associated professor at the Department of Industrial electronics and electrical technologies of Riga Technical University, Riga Technical University, Institute of Industrial Electronics and Electrical Engineering. Member of IEEE Latvia section.

Riga Technical University, Institute of Industrial Electronics and Electrical Engineering

Address: Kronvalda 1, Riga LV1048.

Phone+37167089915, viesturs.brazis@rtu.lv

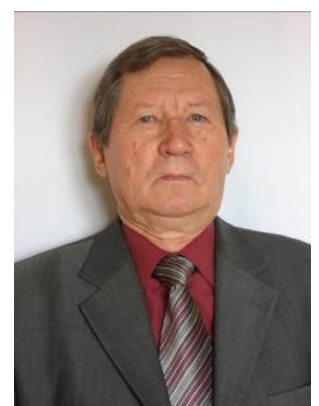

Leonards Latkovskis, Dr. sc. ing. He graduated from Riga technical school in 1957 as technician and Riga Polytechnical institute in 1967 as electro-engineer. Defended his degree of Dr. sc. ing. in 1993 at the Institute of Physical Energetics of Latvian Academy of Sciences.

From 1957-1961 he worked as a technician at Riga factory VEF, from 1961-1966 as an engineer in Riga radio factory (RRR). Since 1966 he works at the Institute of Physical Energetics as an engineer, researcher and senior researcher. Now he is a head of the Laboratory of Power Electronics at the Institute of Physical Energetics and an associated professor at Riga Technical University, Institute of Industrial Electronics and Electrical Engineering. Research interests are connected with Power Electronics and its industrial applications.

Member of IEEE.

Institute of Physical Energetics

Address: 21 Aizkraukles Str., Riga, LV-1006

Phone: +37167558643, leonards.latkovskis@gmail.com 